\title{
ENVIRONMENTAL CHALLENGES OF ECONOMIC DEVELOPMENT
}

\section{Kristijan Ristić}

Poslovni i pravni fakultet, Univerzitet „Union - Nikola Tesla“, Beograd, Srbija

\section{Milanka Bogavac}

Poslovni i pravni fakultet, Univerzitet „Union - Nikola Tesla“, Beograd, Srbija

\section{Branko Petričević}

Fakultet za poslovnu ekonomiju i menadžment, Univerzitet u Travniku, Travnik, Bosna i Hercegovina

CMESTE

JEL Category: F18, 013, Q5

\begin{abstract}
Apstrakt
Svetska ekonomska kriza zajedno sa implementacijom neoliberalnog projekta obelodanila je pomeranja glavnog težišta globalne ekonomije iz sektora proizvodnje u sektor finansija, kao da privredna aktivnost više nije važna. Time je formalizovana primitivna privatna sloboda da se profitira na siromaštvu u formi tajno osmišljene privatne prednosti poput konkurencije, kao ključni podsticaj razvoja i generator monopola. Ekologija je ušla u dnevnu konverziju između dužnika. Dijalog interesa poverilaca i dužnika je izuzetno olakšan primenom specijalnog vida konverzije duga koji se očituje kroz otpis duga (dela) za ekološko očuvanje zelenog kontinenta (debt-for-nature swaps). Današnji svet pati zbog povećanja zagađivanja čovekove okoline i smanjenja ozonskog omotača. I naučnici pate, jer ne znaju da objasne kako će se to odraziti na poljoprivredne prinose, na zdravlje stanovništva, na nivo mora, na dužinu života ljudi, na porast temperature, na društveno ekonomski razvoj, na životni standard građana. Zbog toga, ekološka pitanja postaju sve više ekonomska, mada se ekološki problemi sve više premeštaju u ravan ekonomske nauke, koja već kreira nove finansijske instrumente za simultano rešavanje razvojnih $i$ ekoloških problema. Jedan od najnovijih finansijskih instrumenata, koji je pokazao svu svoju delotvornost, jeste debt-for-nature swaps, putem koga se zaduženim zemljama oprašta deo inostranog duga u zamenu za povećanje investicije države u domenu očuvanja ekoloških dobara od značaja za celu u planetu. U suštini, tim procesom svi zarađuju: zemlja dužnik, jer faktički otkupljuje inostrani dug domaćom valutom i to uz popust, i zemlje poverioci, jer ne moraju da investiraju svež novac za očuvanje čovekove okoline već upotrebljavaju novac od dužnika koji najverovatnije nije ni bio naplativ.
\end{abstract}

Adresa autora zaduženog za korespodenciju: Kristijan Ristić

㫪” kristijanristic.fpim@yahoo.com
Ključne reči: zaštita životne sredine, privredni razvoj 


\section{Abstract}

The global economic crisis along with the implementation of the neoliberal project has announced shifting of the global economy capital center from the manufacturing sector into financial sector, just like the economic activity is no longer important. So, primitive private freedom to capitalize on poverty in the form of secretly designed private benefits such as competition, as a key incentive for the development and monopoly generator was formalized. Ecology has entered a daily conversion between debtors and creditors. Dialog of interests among creditors and debtors is extremely facilitated by using a special type of debt conversion that is manifested through debt write-off for ecological preservation of green continent (debt-for-nature swaps). Today's world suffers from increasing pollution of the environment and the decreasing of the ozone layer. The scientists are suffering too because they do not know how to explain how it will affect agricultural yields, the health of the population, the level of the sea, the length of human life, the rise in temperature, the socio-economic development, the living standard of citizens. Therefore, environmental issues have become more economical, although environmental concerns increasingly moved to the plane of economic science, which has created new financial instruments in order to simultaneously address development and environmental problems. One of the latest financial instruments, which showed all its effectiveness, is a debt-for-nature swaps, through which the indebted countries forgives part of their debt in exchange for an increase in government investment in the field of preservation of ecological heritage that is significant for the whole planet. It is a win-win for everyone: debtor country, because it actually buys off foreign debt using domestic currency with a discount, and the country's creditors, because they do not have to invest fresh money for the preservation of the environment but they are using money from debtors, money that probably was not even payable.

Keywords: environmental protection, economic development

\section{UVODNA RAZMATRANJA}

Zeleni ekonomisti već izrađuju modele za valorizaciju ekoloških troškova i dobiti u nacionalnim ekonomijama kako bi bilansi nacionalnog dohotka prikazivali i promene u prirodnim bogatstvima. Dejstva trošenja prirodnih resursa treba empirijski verifikovati i kroz izmenu SNA (Sistema nacionalnih računa i metodologije UN) u koncept nacionalnog dohotka, uključujući i one prirodne izvore koji su pod kontrolom čoveka. Cilj je, dakle, da bilansi nacionalnog dohotka "pozelene" kako se ne bi više biljke i životinje tretirali različito ("povećanje stočnog fonda jedne zemlje se uračunava onda kada se ono pojavi, ali se prirast komercijalnih šuma beleži onda kada se one poseku)" $U$ sadašnjem obračunu često se nacionalni dohodak naduvava uključivanjem troškova za sprečavanje zagađivanja. To pak znači da se zagađivanje ne računa kao gubitak od društvenog proizvoda. Isto tako, i pad vrednosti prirodnih resursa prikazuje se kao stavka koja preuveličava neto nacionalni proizvod. Jasno je, pri tome, da je izuzetno teško reći koliko košta idila. Ali, uništenje šuma prema tržišnim kriterijumima zasigurno predstavlja zbir gubitaka vrednosti neposečenog drveća i prihoda od drvene građe koji su mogli biti ostvareni. No, i taj kriterijum ne uključuje vrednost koju šume imaju kao staništa životinjskog sveta i kao prostor za rekreaciju ljudi. Zbog toga je važno da se izrada nacionalnog bilansa prilagodi potrebama zaštite čovekove okoline. U početnom stadijumu valjalo bi izgrađivati tzv. bilanse satelite $u$ formi paralelnih bilansa (pored zvaničnih, oficijelnih). Ti "novi" bilansi bi uključivali i promenu kvaliteta prirodne okoline (na primer porast zagađenosti vazduha, izumiranje određenih vrsta biljnog i životinjskog sveta), ali i vrednovanje štete koja se nanosi prirodnim resursima koji nisu tržišno vrednovani. Kod resursa, koji nemaju tržišnu vrednost, kontroverzno je pitanje šta treba meriti: (a) da li trošak restauracije prirodne sredine $u$ prvobitno stanje ili (b) sumu koju bi potrošači bili skloni da potroše radi poboljšanja kvaliteta životne sredine. Sve u svemu, konvencionalne modele za određivanje bogatstva valja proširiti i obogatiti kako bi se dali adekvatni odgovori "zelenima" koji populariše nove kalkulacije i obračune.

\section{PRIVREDNI RAZVOJ I EKOLOŠKI MENADŽMENT}

Američki ekonomisti već se zalažu za nov način izračunavanja nacionalnog blagostanja $i$ to ne 
samo preko bruto nacionalnog dohotka. Po Robertu Konstanzi i Lajzi Vajgner nova računica treba da uključi doprinos prirode ekonomiji. Oni navode primer da društveni proizvod uzima u obzir samo vrednost drveta posečenog u šumi, ali ne i to što šuma čuva zemljište, čisti vazduh i vodu, omogućava život divljači, pruža rekreaciju i zabavu. Zbog toga se Konstanza i Vajgner zalažu da se u ekonomsku računicu uključi prirodno bogatstvo, kao što je zemljište i atmosfera, biljna i životinjska biomasa. Oni su, u tom kontekstu, izračunali da vrednost hektara močvarnog zemljišta uz obalu Luizijane nije 1.250 dolara (za koliko se prodaje), već između 6.250 i 42.500 dolara kad se uzme u obzir to što su posetioci spremni da plate za komercijalni ribolov, lov, rekreaciju i zaštitu od oluja. Kao osnov uzeli su podatke o tome koliko korisnici plaćaju put $u$ to područje i dodali su vrednost sunčeve energije akumulirane u biljkama koje su baza za ribe i divljač, čija se ekonomska vrednost može meriti.

$\mathrm{U}$ teoriji i praksi na pomolu je nova kombinacija ekologije i marketinga u formi ponude nove serije proizvoda oslobođenih štetnih supstanci. Propagande i promotivne kompanije sada izbacuju etikete zdravog i zelenog, što više nije samo problem marketinga, već i sudova časti. Tako se pristiglo i do zelenog marketinga kao nove grane marketinške teorije i prakse odnosno svrsishodne koalicije marketinga i ekologije. Kreatori zelenog marketinga ekološko uništavanje prirode upoređuju majstorski sa opakim bolestima koje ne bole, ali koje neprimetno odnose ljudske živote. $U$ ekološkom marketingu obično se naglašava da prirodne blagodeti nisu na raspolaganju u neograničenim količinama. Zato valja voditi računa da "novi i novi" proizvodi ne opterećuju okolinu kroz ekološki nekontrolisanu proizvodnju, čiji su menadžeri često profiterski zaslepljeni. Tehnološki menadžment iz neznanja ekonomije prirode kreira nove tehnologije koje uništavaju okolinu. A svaka "tehnološka isporuka" mnogo košta i sa stanovišta vremena i sredstava, i sa stanovišta učinjene ekološke štete. I ekološki oporavak zahteva nova ulaganja. Konačno, zaštita okoline javlja se kao novi ograničavajući faktor na putu uvećavanja kapitala, jer dodajni ekološki troškovi u dugoročnom trendu mogu da degradiraju, oplodnju kapitala. (Marković, Ilić, \& Ristić, 2012)
Danas se i ograničavanje stope rasta ispuštanja ugljen dioksida može rešavati na ekonomski način (pored već poznatog tehnološkog racionalisanja upotrebe energije). Visoki troškovi novih tehnologija, koje redukuju ispuštanje ugljen dioksida, sa ekonomskog stanovišta nemaju opravdanje iz prostog razloga što nametnuto povećanje proizvodnih troškova iz ekoloških motiva smanjuje konkurentnosti, firme i tržišnu kompetitivnost zemlje. Zbog toga je lansiran sistem u kome sve države savremenog sveta dobijaju dozvole za zagađivanje (na osnovu dozvoljene količine ugljen dioksida). "Ideja o međunarodnoj trgovini kvotama za zagađivanje je zaokupila svetsku pažnju, jer omogućava svakom ekonomskom agentu (u ovom slučaju državi) da bira da li želi da investira u tehnologiju koja će sputavati dalje zagađivanje ili želi da otkupi pravo neke druge države (koja zagađuje ispod svoje kvote) i tako nastavi da proizvodi sa starom tehnologijom. Potencijalno tržište za investiranje u nove tehnologije za reduciranje zagađenosti na ekonomsko-ekološkim principima jesu gotovo sve postsocijalističke zemlje, koje bi na jeftiniji način došle do svežeg kapitala. (Marković, llić, \& Ristić, 2012)

Ekološke sile današnjice nisu samo ikonografije "novog sveta" nego i neumoljivi pokazatelji prikrivenih tendencija i povremenih erupcija modernog varvarstva preobučenog u državni interes, ekotehnološku dominaciju, vojnoindustrijski kompleks i etnocentričku politiku. Neodgovorne političke elite već rasipaju nacionalno bogatstvo, prekomerno eksploatišu prljavu tehnologiju i neekonomski iscrpljuju prirodne resurse. Destrukcija sistema tako prelazi u destrukciju ljudi u vidu razaranja materijalne $i$ duhovne kulture, ljudske psihe i morala, životne i radne okoline. Ekološki standardizovana hrana sveta je rezervisana samo za najelitnije segmente bogatog sveta, dok je zagađena hrana prikovana kao privilegija samo za crne koji uopšte nemaju šta da jedu. Tako se nasrnulo na čoveka i na ljudska osnovna prava uopšte, čak i u monolitnim društvima čija se ruinirana ekonomsko-tehnološka struktura raspada jednako kao i njihova ideološka matrica.

Prelaz u postindustrijsko društvo imao je za cilj stvaranje kvalitativno novih uslova za ekonomski rast i tehnološki razvoj, koji u razvojnu igru ubacuju nove sofistikovane ekonomske faktore, 
kao što su znanje, informacije, nove tehnologije, upravljanje inovacijama. Filozofi - humanisti, teoretičari nekonvencionalni ekonomisti i praktičari - aktivisti čak su preokrenuli ekološki pogled na svet. Sa globalnog stanovišta, svi se ekonomsko-ekološki problemi opserviraju kao planetarna pitanja u strukturi vladajućih doktrina i naučnih paradigmi današnje ekonomije, socijalne teorije, prirodne nauke i tehnologije. Ekološka racionalnost, ponovo razotkriva činjenicu da je očuvanje prirodnih resursa i uspostavljanje prirodne ravnoteže na kojima počiva današnji život, refleksija nove ekonomske filozofije u kojoj je prihvaćena ekološka standardizacija, redukcija tehnološkog i potrošačkog zagađivanja, eko reciklaža, ekološko zakonodavstvo i edukacija, ekološka istraživanja i ulaganja u zaštitu ljudskih bića i njihovu duhovnu kulturu, psihičku ravnotežu, mentalno i moralno zdravlje ljudi. (prema: (Vandana, 1994))

\section{GLOBALNI EKOLOŠKI IZAZOVI VS IZAZOVI PRIVREDNOG RAZVOJA}

Kako ekosistemi i njihovo globalno stanje određuju biogeohemijske i biofizičke procese kojima se reguliše celokupni sistem funkcionisanja Zemlje, moguće ekološke i klimatske posledice gubitka biodiverziteta sve više zaokupljaju pažnju naučne i stručne javnosti. Nastavljanje gubitka biodiverziteta može ugroziti dugoročnu sposobnost ekosistema da regulišu klimu, može ubrzati globalno zagrevanje i voditi ka dodatnim i potencijalno ireverzibilnim promenama sistema na Zemlji. Gubitak biodiverziteta i degradacija ekosistema trebalo bi, saglasno tome, da predstavljaju jedan od najznačajnijih izazova za one koji odlučuju o sudbini planete i ljudi na njoj $u$ budućnosti.

Osnovni faktori koji dovode do gubitka biodiverziteta mogu se svrstati u nekoliko grupa: (1) promene staništa, (2) pojava invazivnih autohtonih vrsta, (3) zagađenja, (4) rast broja stanovnika i (5) preterana eksploatacija.

Većini vrsta neophodno je neporemećeno stanište - nezagađeno mesto za pronalazak hrane, vode, skloništa i partnera. Ljudske aktivnosti su odgovorne za narušavanje statusa staništa širom sveta. Kako bi zadovoljio svoje potrebe za staništem i ekonomskim aktivnostima, čovek krči šume, isušuje močvare, preorava prerije i stepe, vrši ispašu stoke na nekada nenarušenim pašnjacima, a da se pri tom hiljade međusobno povezanih biljnih i životinjskih vrsta koje žive na tim staništima zamenjuju jednom vrstom žitarica ili jednom vrstom drveća, odnosno monokulturama. Ljudska naselja se prostorno šire, zauzimajući prirodna staništa. U Sjedinjenim Američkim Državama od preko 1,4 miliona kvadratnih kilometara prvobitne prerije sa visokom travom danas je preostao samo jedan procenat. Velike količine vremena, energije i novca se kasnije troše da bi se održali ti neautonomni ili polu autonomni ekosistemi (monokulture) od neprekidne masovne invazije oportunističkih vrsta biljaka (korova), mnogih vrsta insekata koje se pojavljuju kao štetočine, kao i čitavog niza drugih patogenih vrsta (gljive, virusi, bakterije) koje uzrokuju niz oboljenja na biljkama koje se uzgajaju. (Ristić, 2014)

Namerno ili slučajno, ljudi često donose biljne ili životinjske vrste na nove teritorije, gde one imaju malo ili uopšte nemaju prirodnih predatora koji regulišu brojnost njihovih populacija. Ove invazivne vrste - takođe nazvane „alien", introdukovane ili egzotične vrste - važe za drugi po opasnosti faktor gubitaka u biodiverzitetu, odmah posle uništavanja staništa. Na primer, invazivne vrste su odigrale značajnu ulogu u remećenju statusa 35 do 46 procenata od svih vrsta koje se trenutno smatraju ugroženim u SAD. Invazivne vrste mogu takođe da naruše cikluse u kojima se javljaju požari, kruženje nutrijenata, hidrološke i energetske rezerve ekosistema u koje se unesu.

Sa druge strane, više ljudi na planeti istovremeno znači i veći broj izmenjenih i narušenih staništa, viši nivo zagađivanja, veći nivo prekomerne eksploatacije bioloških resursa i veći broj invazivnih i introdukovanih vrsta. Zagađenje koje se javlja u mnogim formama - izlivanje nafte, kisele kiše i kisele magle, toksične hemikalije u veštačkom đubrivu i pesticidima, otpadne vode, deponovanje otpada kako iz urbanih tako i saburbanih područja - može momentalno da izazove smrt organizma ili može da ga oslabi, utičući na njegovu mobilnost i sposobnost za reprodukciju. Pesticidi, kojima se želi kontrolisati brojnost nekih vrsta insekata, štetočina poljoprivrednih kultura istovremeno eliminišu i mnoge vrste insekata oprašivača, uključujući populacije domaće medonosne pčele, što za uzvrat može da izazove smanjenje roda useva. 
Otpadne vode koje se ulivaju u reke, jezera i obalne ekosisteme izazivaju negativan efekat na ceo akvatični ekosistem. Naročitu brigu izazivaju hemikalije koje izazivaju probleme žlezda sa unutrašnjima lučenjem kao što su DDT, DDE i PCB. Ove supstance oponašaju ili utiču na rad normalnih hormona u živim organizmima. Anomalije u razmnožavanju su otkrivene kod aligatora, galebova i lososa izloženih visokim nivoima hemikalija iz pesticida i životinjskih hormona u njihovom okruženju. (Ristić K. , 2015)

Posebnu pretnju po biodiverzitet danas predstavlja preterana eksploatacija kao rezultat privrednih aktivnosti. Aktuelni intenzitet seče šuma preti da eliminiše mahagoni i druge vrste drveća kojima je potrebno mnogo godina da izrastu i budu spremne za reprodukciju. Deset milijardi dolara je godišnja vrednost svetske trgovine divljim vrstama, koje se koriste za ljubimce, narodnu medicinu, gurmansku ishranu, dekorativne objekte i ostalo. Sve ovo ugrožava slonove, nosoroge, nilske konje i živopisne korale, tropske biljke i ptice, medvede, pande i tigrove. Svake godine potrošači u SAD kupe oko 12000 jedinki primata, 2,5 miliona orhideja, 200000 živih ptica, 2 miliona gmizavaca, 250 miliona tropskih riba i veliki broj produkata divljih životinja. Pri tom blizu jedne četvrtine trgovine divljim vrstama počiva na krivolovu.

Prema izveštaju Evropske agencije za zaštitu životne sredine (EEA, 2007), biodiverzitet u Evropi je u opadanju i nastavljanje gubitaka ekosistema započeto u prethodnom periodu i dalje predstavlja veliki problem.

Problemi zagađenja (pre svega u industrijalizovanim zemljama Zapada) pokrenuli su sedamdesetih i osamdesetih godina prošlog veka pitanja zaštite životne sredine i održivog razvoja, o čemu je bilo reći u prethodnim poglavljima. Jačanje invajronmentalizma poklapa se sa shvatanjem da se uticaji na životnu sredinu ne mogu više smatrati izolovanim problemima države ili regiona u kome su nastali. Od tada je prošlo više decenija, a problemi zagađenja su se samo uvećavali.

Između 2000. i 2007. godine emisije u atmosferu ugljeničnih gasova od sagorevanja fosilnih goriva porasle su za 22 procenta na oko 8,2 milijarde tona (Sheehan, et al., 2007). Od ovog enormnog povećanja najveći deo otpada na Kinu (57\%), i
Indiju ( $8 \%$ ), dok SAD učestvuje sa 4 procenta, a cela Evropa sa samo 3 procenta. Međutim, i pored kineskog dramatičnog povećanja emisije ugljeničnih gasova, još uvek je količina po stanovniku u SAD četiri puta veća od odgovarajuće količine u Kini. Ima mnogo različitih izvora zagađenje vazduha, ali se kao najznačajniji izdvajaju saobraćaj i industrijski izvori. Najveći industrijski izvori aero zagađenja u svetu su termoelektrane, posebno one koje sagorevaju ugalj. Termoelektrane zagađuju vazduh ispuštanjem ugljeničnih, sumpornih i azotnih oksida, ali $\mathrm{i}$ jedinjenja žive $\mathrm{i}$ čađi $\mathrm{i}$ pepela. Energetska zavisnost pojedinih gusto naseljenih zemalja od sagorevanja fosilnih goriva preti da nivo zagađenja vazduha višestruko uveća u budućnosti- Kina, na primer, planira da do 2012 godine gradi sto termoelektrana godišnje, kako bi zadovoljila svoje narasle apetite za energijom potrebnom za razvoj. Ovakvi poduhvati praćeni su mnogim negativnim efektima u samoj Kini, ali i u celom regionu: sredinom devedesetih godina prošlog veka došlo je do smanjenja prinosa u poljoprivredi Kine za 4,3 procenta zbog acidifikacije zemljišta i taloženja pepela, zabeležene su ekstremne vremenske nepogode (poplave, nevremena i suše), zbog kojih je umrolo 2300 ljudi, raseljeno preko 13 miliona i pretrpljena ekonomska šteta od blizu 24 milijarde dolara. Emisije iz saobraćaja su takođe sve veće zbog povećanja broja vozila i frekvencije drumskog i avio saobraćaja. U Evropi je, na primer, prevoz robe u drumskom saobraćaju u protekloj deceniji porastao za blizu 50 procenata, dok je porast avio saobraćaja bio 67 procenata. To je uslovilo porast emisija azotnih oksida za 55\% i ugljenmonoksida za čak $75 \%$. (Ristić K. , 2015)

Veoma je značajno uočiti jasnu vezu između siromaštva i zagađenja. Siromaštvo prouzrokuje rizike u životnoj sredini koji ugrožavaju svakog pojedinca: osim nedostatka čiste vode za piše i sanitarnih uslova, stanovnici u siromašnim zemljama u razvoju često su izloženi različitim vrstama zagađenja, a da uz to nemaju dovoljno mogućnosti da se sa ovim rizicima bore. Kako uglavnom nisu u mogućnosti da priušte čiste izvore energije, siromašni zavise od sagorevanja uglja ili biomase za potrebe domaćinstva. Njihove kuće se u mnogo slučajeva nalaze u blizini prometnih saobraćajnica, smetlišta, ili industrijskih postrojenja. Visok nivo urbanizacije veoma 
pogoduje pogoršanju uslova života siromašnih slojeva stanovništva, izlažući in dodatno opasnim ili toksičnim polutantima. $U$ najvećem broju zemalja u razvoju zakoni i regulatorne institucije za zaštitu od zagađenja još uvek ne postoje, ili su neadekvatni, što omogućava nekontrolisano zagađivanje uz nedovoljnu svest o posledicama. Štaviše, mnoge supstance zabranjene zbog svojih efekata u razvijenim zemljama, u slobodnom su prometu i čak se proizvode u nerazvijenim zemljama, često za izvoz u razvijene. Rezultat svega toga su neprocenjivi efekti po ljudsko zdravlje, izazvani zagađenjem na radnom mestu, u kući i na otvorenom prostoru.

Bližimo se vremenu kada će potreba za vodom premašiti zalihe. Nakon toga prestaje razvoj, počinje borba za vodu, a postoji čak i opasnost od ratnih sukoba. Stručnjaci tvrde da se zvona na uzbunu ne oglašavaju bez razloga. Godišnja potrošnja vode u svetu stalno raste. Zbog toga što se izvori čiste vode ne uvećavaju, već se usled korišćenja, zagađenja i klimatskih promena, velikom brzinom smanjuju, a broj stanovnika osetno raste, Svetska komisija za vodu upozorava na to da bi do 2025. godine dve trećine stanovništva moglo da se suoči $s$ ozbiljnim nedostatkom vode.

Količina vode na Zemlji je nepromenljiva. Od ukupne količine vode, koja se procenjuje na blizu 1,4 milijardi kubnih kilometara, samo 0,01 procenat otpada na vodu koja nije slana, lako je dostupna i nalazi se na površini Zemlje u rekama i jezerima. Petina vode koja se koristi širom sveta dobija se crpljenjem podzemne vode.

Značaj vode je evidentan u svakom promišljanju zahteva za održanje na planeti. Voda predstavlja fundamentalni uslov života i ljudskog opstanka, ali, uz to, u velikoj meri utiče na ekonomske aktivnosti (kako na proizvodnju, tako i na potrošnju) i društveni razvoj. Do nedostatka vode dolazi kada zahtevi za vodom, generisani demografskim rastom, premaše lokalne nivoe snabdevanja, odnosno ponude (Turton \& Warner, 2002). Kada govori o nedostatku vode, Sekston (Sexton, 1992) razlikuje apsolutni i ekonomski nedostatak. Do apsolutnog nedostatka vode dolazi kada nepostojanje odgovarajuće tehnologije ograničava snabdevanje vodom. Ekonomski nedostatak vode odnosi se na ekonomski izbor obezbeđivanja vode, pri čemu je neophodno široko učešće svih nivoa društva u procesu obezbeđivanja i distribucije (JohnsonWelch, 2000). Učešće svih ima veliki značaj za dolaženje do pogodnih i prihvatljivih rešenja za upravljanje vodnim resursima i dugoročnu održivost takvih rešenja. (prema: (Harris, 2009)).

Svet današnjice je u snažnom zagrljaju globalizacije. Ekonomske, tehnološke, političke i ekološke mreže obavijaju Zemlju, polako bacajući u zaborav vrednosti nacionalne države, suvereniteta, kulturnog identiteta. Sa završetkom hladnog rata, liberalizacijom trgovine $u$ svetu $i$ rastućim uticajem multinacionalnih korporacija, ekonomski uticaji nastali u pojedinim delovima sveta prelivaju se u druge regione. Komunikacijske mreže poput telefona, televizije i interneta doprinele su da informacije postaju dostupne gotovo istovremeno kada i nastaju. Rastuće svetsko stanovništvo postaje zavisno od iste brze hrane, „blokbaster" filmova, istih potrošnih dobara i globalne kulturne ponude.

Prevladavajuće shvatanje razvoja se menja u relativno pravilnim vremenskim intervalima: dominantne ideje se odbacuju i posle nekog vremena ponovo aktueliziraju. Primeri za to su brojni - značaj koji se daje unutrašnjim i eksternim faktorima koji utiču na razvoj, uloga tržišta i uloga države, ciklične promene razvojnog optimizma u razvojni pesimizam i obrnuto. Ponekad se čini da na smenjivanje ovih ciklusa utiče i pomodno prihvatanje ili neprihvatanje ekonomskih ili političkih teorija, koje odlučujuće utiče na postojeće političko okruženje. Pre četrdeset godina postojalo je opšte prihvatanje Kejnezijanskog pristupa, da bi pre dvadeset godina on bio odbačen od svih i zamenjen neoliberalnim.

Što se tiče odnosa ideja koje propagiraju institucionalisti, „zeleni" i bioinvajronmentalisti o njima govore kao o čaši vode kojom se pokušava gasiti požar. Globalni ekonomski sporazumi, po njima, uticali su veoma malo na stvarno rešavanje problema. „Zeleni" i bioinvajronmentalisti se, međutim, ne slažu zbog čega je do toga došlo. Bioinvajronmentalisti smatraju da je moć globalnih institucija preslaba da bi bila efektivna. Za razliku od njih, „zeleni" tvrde da usmeravanje na globalne institucije predstavlja pogrešnu strategiju, zbog toga što se u ovim institucijama teško može osetiti uticaj onih koji su najugroženiji promenama u 
Životnoj sredini, čime se doprinosi da ovi sporazumi ne budu efikasni.

\section{PREDUZETNIČKA „ZELENA“ EKONOMIJA I PRIVREDNI RAZVOJ}

$\mathrm{Za}$ svaku transnaciona1nu kompaniju (korporaciju) poslovni uspeh postaje sve zavisniji od preciznog predviđanja budućih trendova u poslovnom okruženju, firme. Upravljačke strukture $\mathrm{u}$ razvijenim tržišnim privredama prinuđene su da respektuju rasprostranjeno mišljenje populacije koja već odbija da prihvati visok stepen degradiranosti okoline. A kada je okolina u pitanju, kompanije su prinuđene da poslovno odgovornije reaguju na zabrinutost javnosti za neminovno zagrevanje planete. Nastupajuće poslovne godine jesu predstojeći izazovi poslovanja preduzeća, pošto ekologija postaje opredeljujući faktor biznisa u budućnosti. Vodeći svetski menadžeri već se pomno pripremaju da odgovore zahtevima strogog ekološkog zakonodavstva i zahtevima potrošača, koji sve više insistiraju na ekološkoj komponenti kvaliteta proizvoda. (prema: (Saks, 2015)).

Privrednici osećaju svoju ključnu ulogu u zaštiti okoline, pošto su već shvatili da su poslovni procesi dominantan izvor pritisaka na životnu sredinu. I kao što je zapošljavanje ključni preduslov socijalnog osiguranja, tako je i zaštita okoline postala vodeći preduslov poslovanja preduzeća. Ekološki senzibilna javnost pruža šansu profitno orijentisanim menadžerima da oboje "zeleno" poslovno planiranje i da diversifikuju pristupe organizaciji poslovanja, knjigovodstvu, bilansiranju uspeha, poslovnim finansijama, marketingu, menadžmentu i odnosima s javnošću, kako bi se stekla ekološka reputacija, koja predominantno, opredeljuje odluke potrošača o kupovini (ekološki kvalitetnih) proizvoda. Ekološki prosvećeni potrošači u civilizovanim društvima tržišne orijentacije spremni su da koriste (na organizovan način) potrošačku moć i na tržištu i da vrše pritisak na industriju. Proizvođači su već, osetili da tražnja ekološki, prihvatljivih proizvoda beleži uzlazni trend na razvijenim tržištima savremenog sveta. $U$ međunarodnim razmerama, dramatičan zaokret u preferencijama potrošača "guta" dodatna ekološka troškovna opterećenja. Nova poslovna filozofija mora posebno da vodi računa o relativno snažnom segmentu sektora stanovništva koji je voljan da plati proizvode koji zadovoljavaju ekološke standarde. Međutim, menadžer mora da vodi računa o neumitnoj istini da će određeni proizvodi postati neprihvatljivi za potrošače ekološkog kvaliteta. U kratkoročnim vremenskim sekvencama multinacionalne kompanije mogu ostvarivati visoke profite zaobilaženjem ulaganja u ekološka istraživanja kvaliteta proizvoda. Ali, u dugoročnim -vremenskim sekvencama ove kompanije stiču imidž ekološki neosetljive kompanije, gube mesto na visoko kompetitivnom tržištu, kasne u prestrukturiranju proizvodnih programa i teže podnose stroge ekološke standarde u budućnosti.

Ekološki pritisci javnosti iznudili su ubrzanu transformaciju vrednovanja menadžerskog uspeha, koji, pored uobičajenih upravljačkih performansi zasnovanih na rastu kvantumu profita, inkorporira i dugoročnu komponentu sposobnosti razvijanja timova, koji, i poslovno i ekološki, uspešno uvode kompaniju u 21.vek, sa usredsređenošću kompanije na ekološke probleme, sa visokim eko1oškim mora1om zaposlenih, sa perfekcioniranom proizvodnjom tzv, zelenih proizvoda. I poruke javnog mnjenja savremene zapadne civilizacije idu u temi pravcu iz prostog razloga što su kompanije u potpunosti odgovorne za uticaj svojih proizvoda i za pritisak svojih tehnologija na životnu okolinu. Menadžeri su ekološki, pritisnuti javnim mnjenjem, a kompanije su suočene sa ekološkom odgovornošću pred zakonom. $U$ tom smislu, kompanije sa svojim menadžerima formulišu interne ekološke programe i time preuzimaju punu odgovornost, za polutante, koje emituju, i za recikliranje. Brojne kompanije već tragaju za ekološkom perfekcijom i za redukcijom ekoloških rizika koji su inherentni proizvodnim procesima $\mathrm{i}$ proizvodima. Budući ekološki monitoring imaće za zadatak da osmotri negativne uticaje na okolinu i poštovanje ekoloških standarda, sa izvedenim efektima na planu podizanja nivoa ekološke svesti i uštede firmi. Monitoring timovi imaće priliku da upoređuju ekološke performanse proizvodnih procesa i proizvoda sa ekološkim standardima i, da obezbeđuju njihovu usklađenost, bez obzira, na to što ekološko sučeljavanje troškova i koristi stvara probleme u poslovanju kompanije. No, i pored toga, budućnost na tržištu pripadaće samo kompanijama sa ofanzivnom ekološkom 
strategijom razvoja proizvoda čiji industrijskoproizvodni ciklus anglobira četiri faze u vidu:

- ekstrakcije sirovina,

- proizvodnja robe,

- upotrebe proizvoda i

- odlaganja proizvoda posle upotrebe (i reciklaža).

Tome se sada pridodaju zahtevi za minimiziranjem ekoloških uticaja proizvoda, kojima istekne vek upotrebe, i za eliminisanjem uočenog problema deponovanja otpada. $U$ ekološki redefinisanoj poslovnoj strategiji, kompanije postaju potpuno odgovorne za životni ciklus proizvoda, počev od faze proizvodnje pa sve do faze otpada i ponovne upotrebe. Proizvodni procesi budućnosti, samim tim, moraju biti podešeni rekreiranju kružnog toka i inputa i autputa sa modularnim dizajnom, koji kombinuje relativno kratke tehnološke cikluse i dugi rok upotrebe proizvoda sa recikliranjem. (prema: (Saks, 2015)).

\section{ZAKLJUČNA RAZMATRANJA}

Dijagnostički aspekt ekološke sfere pokazuje da zemlja nije više beskrajni izazov prostora već konačan termo dinamičan sistem i da kriza okoline nije više samo entropija ekosistema već posledica neadekvatne društvene organizacije, prevaziđenog načina proizvodnje i klimakteričnog razvoja proizvodnih snaga.

Suština politike zaštite čovekove sredine ne ogleda se samo u usklađivanju društveno ekonomskog, socijalnog i tehnološkog razvoja nego i u usklađivanju ekonomskog, privrednog i ekološkog razvoja. To je ta novina na koju kreću pažnju teoretičari koji doprinose afirmaciji shvatanja da očuvanje i unapređenje čovekove sredine postaje "prvorazredna kategorija $u$ sistemu vrednosti društva" i razvoja privrede u celini.

\section{CITIRANI RADOVI}

EEA. (2007). EEA environmental statement 2007. Luxembourg: EMAS.

Harris, J. (2009). Ekonomija životne sredine i prorodnih resursa. Beograd: Data status.

Johnson-Welch, C. (2000). Gender and Household Food Security: A Lost Opportunity. International Food and Nutrition Conference 2000 (pp. 8-10). Tuskegee University.

Marković, D. Ž., llić, B. B., \& Ristić, Ž. L. (2012). Globalna ekonomija. Beograd: EtnoStil.

Ristić, K. (2014). Ekonomija održivog razvoja. Beograd: Etnostil.

Ristić, K. (2015). "Green economy" and new bussines strategy. EMFM 2015, Proceedings. Zenica: University of Zenica.

Saks, D. (2015). Doba održivog razvoja. Beograd: Data status.

Sexton, K. (1992). The role of scientific research in risk assessment and risk management decisions. Otolarnygol Head Neck Surg, 106(6), 635-641.

Sheehan, M. O., Chafe, Z., Flavin, C., Halweil, B., Hughes, K., Kenworthy, J., . . Soots, L. (2007). 2007 State of the world - Our urban future. New York: The World watch Institute.

Turton, A., \& Warner, J. (2002). Exploring the population/water resources nexus in the developing world. In G. Debelko, Finding the source. Washington DC: Woodrow Wilson Center.

Vandana, S. (1994). Conflicts of global ecology: Environmental activism in a period of global reach. Alternatives(19), 195-207.

Datum prve prijave:

Datum prijema korigovanog članka:

Datum prihvatanja članka:
27.04.2016.

08.05.2017.

20.05.2017. 
Kako citirati ovaj rad? / How to cite this article?

Style - APA Sixth Edition:

Ristić, K., Bogavac, M., \& Petričević, B. (2017, July 15). Ekološki izazovi privrednog razvoja. (Z. Čekerevac, Ed.) FBIM Transactions, 5(2), 109-117. doi:10.12709/fbim.05.05.02.12

Style - Chicago Sixteenth Edition:

Ristić, Kristijan, Milanka Bogavac, and Branko Petričević. "Ekološki izazovi privrednog razvoja." Edited by Zoran Čekerevac. FBIM Transactions (MESTE) 5, no. 2 (July 2017): 109-117.

Style - GOST Name Sort:

Ristić Kristijan, Bogavac Milanka and Petričević Branko Ekološki izazovi privrednog razvoja [Journal] // FBIM Transactions / ed. Čekerevac Zoran. - Belgrade - Toronto : MESTE, July 15, 2017. 2 : Vol. 5. - pp. 109-117.

Style - Harvard Anglia:

Ristić, K., Bogavac, M. \& Petričević, B., 2017. Ekološki izazovi privrednog razvoja. FBIM Transactions, 15 July, 5(2), pp. 109-117.

Style - ISO 690 Numerical Reference:

Ekološki izazovi privrednog razvoja. Ristić, Kristijan, Bogavac, Milanka and Petričević, Branko. [ed.] Zoran Čekerevac. 2, Belgrade - Toronto : MESTE, July 15, 2017, FBIM Transactions, Vol. 5, pp. 109117. 